\title{
Patlatma Kaynaklı Titreşimlerin Azaltılmasında Yüzey Dalgalarının Bastırılması Yönteminin Uygulanması: TKİ YLİ Milas İşletmesinde Bir Uygulama
}

\author{
Application of Surface Wave Mitigation Method in Minimizing Blast-Induced Vibration: \\ A Practice at TKI YLI Milas Enterprise
}

\author{
Güzin Gülsev UYAR ALDAŞ ${ }^{1}$, Berkan ECEVITOĞLU ${ }^{1}$, Aslı Zeynep CAN ${ }^{1}$ \\ ${ }^{1}$ Ankara Üniversitesi Mühendislik Fakültesi Jeofizik Mühendisliği Bölümü, Tandoğan, Ankara
}

\begin{abstract}
Özet: Patlatmalı kaya kazısı yapılan yerlerde, patlatmaların çevre yerleşim birimlerine olan olumsuz etkileri arasında sismik titreşimler önemli yer tutmaktadır. Söz konusu titreşimleri en aza indirebilmek için alışılagelmiş "Hasar sınırlarının altında kalabilmek için gecikme başına düşen en büyük patlayıcı miktarını belirleme" yöntemi kullanılmaktadır. Bu çalışmada Türkiye Kömür İşletmeleri (TKİ) Muğla İli Yeniköy Linyitleri İşletmesi (YLİ) ocaklarındaki patlatma kaynaklı titreşimleri en aza indirebilmek için, mevcut yöntemden farklı olarak, yüzey dalgalarının bastırılması prensibine dayanan yeni bir yöntem kullanılmıştır. Yeni yöntem sadece sismik dalga ile ilgilenir ve sismik dalgaların birbirleriyle yıkıcı girişimlerini sağlayacak en uygun gecikmelerin verilmesini hedefler. Yöntemin en can alıcı noktası, pilot patlatmaya ait sismik sinyalin kullanılarak grup patlatmaya ait sismik sinyalin modellenmesidir. Pilot sinyal, ilerlediği hat boyunca karmaşık jeolojiyi de üzerinde barındırdığı için, grup patlatmanın modellenmesinde herhangi bir varsayıma ve jeolojik modellemeye gereksinim duyulmaz. Bölgede daha önceki yıllarda alışılagelmiş yöntemle titreşimler azaltılmaya çalışılmıştır ancak şikayetlerin devam etmesi üzerine bu çalışma yapılmıştır. Bu yöntemle, madencilik faaliyetlerinde kısıtlamaya gitmeden, sadece uygun gecikme elemanları ile patlama gruplarını ayarlayarak, titreşimler hedef noktalarda en aza indirilebilmişlerdir.
\end{abstract}

Anahtar Kelimeler: Patlatma, titreşim, hasar, maden, taş ocağı.

Abstract: Seismic vibration is very important among the environmental impacts of rock blasting operations. Classical method to minimize these vibrations is "determination of maximum amount of explosive per delay that will not cause any damage to the environment". In this study, a new method was used to mitigate blast-induced ground vibrations caused by Turkish Coal Interprises (TKI) Muğla Yeniköy Lignite Interprises (YLI). The method is quite different from conventional methods. It considers only seismic waves and aims to employ the most suitable time-delays among blast-hole groupings to minimize destructive interference of the surface waves at the target location. The crucial point of the method is the use of a pilot blast signal to model the group blast signal. Since the pilot blast signal takes account of the seismic properties of all complex geology between the blast and the target locations, it does not require any geological model or assumption. In the previous years, blast vibrations in the region were tried to be minimized by conventional methods but this study was conducted due to continuity in complaints. By this method, blast vibrations could be minimized only by arranging suitable delays between blast groups without any restrictions in mining operations.

Key Words: Blasting, vibration, damage, mine, quarry.

\section{Giriş}

Patlatma yolu ile kaya kütlelerini kırma faaliyeti, maden, taş ocakları, yol, tünel, baraj, inşaat ve alt yapı çalışmalarında kabul gören en güçlü ve en ekonomik yöntemdir. Artan rekabet, çevre koruma ve güvenlik tedbirleri gibi unsurlar, yeni patlatma tekniklerinin geliştirilmesini zorunlu kılmıştır. Bütün bu gelişmeler, patlatmalar sonucu çevreye verilebilecek taş savrulması, hava şoku, toz emisyonu ve patlatma titreşimleri gibi etkileri de beraberinde getirmektedir. Bunlar arasında en fazla şikayet konusu olan ise patlatmalardan kaynaklanan titreşimlerdir. Çünkü gerek taş savrulması ve gerekse hava şoku ve toz emisyonu patlatma noktasına yakın bölgelerde etkin olabilirken patlatma titreşimleri çok uzaklarda da kendini hissettirebilmektedir. Bilinçli ve duyarlı işletmeler, patlatmaların yarattığı bu olumsuz etkiyi asgari düzeyde tutabilmek ve çevreye zarar vermemek için gerekli ölçüm ve değerlendirme çalışmalarını yapmak ya da yaptırmak zorundadırlar.

Patlatma kaynaklı sarsıntıların çevre yerleşim yerlerine olan etkilerinin belirlenmesi ve minimize edilmesinde alışılagelmiş yöntem, sismografla en yüksek parçacık hızlarının belirlenmesi, patlatma ile ölçüm alınan yer arasındaki güzergah için arazi katsayılarının saptanması, sarsıntının yayılma kuralını belirleyen ampirik formülün bulunması ve bu formül kullanılarak yapılan patlatmalar için mesafeye bağlı olarak bir seferde güvenle ateşlenebilecek en yüksek patlayıcı madde miktarlarının saptanmasıdır (Bollinger, 1971; Siskind vd., 1980; Anderson vd., 1982; Dowding, 1985; 
Siskind vd., 1989; Anderson,1993; Persson vd., 1994; Muller, 1997; Muller ve Hohlfeld, 1997; Hoshino vd., 2000; Siskind, 2000; Chen ve Huang, 2001; Tripathy ve Gupta, 2002; Adhikari vd., 2004)).

Alışılagelmiş yöntemde sadece en yüksek titreşim değerleri esas alınmakta, tüm dalga biçiminin analizini kapsayan değerlendirmelerden uzak durulmaktadır. En yüksek tanecik hızlarına karşılık gelen ölçekli mesafelere göre hesaplanan ampirik formül ile, kullanılan patlayıcı miktarlarına kısıtlamalar getirerek titreşim düşürülmek istenmektedir. Etkin frekanstaki en yüksek tanecik hızını esas alan bu değerlendirmede, bu frekanslar civarındaki daha düşük genlikli fakat uzun sürdüğü için daha fazla hasar verebilecek titreşim dalgaları gözardı edilmektedir. Bu durum, bu yöntem ile elde edilen ampirik formüllerin güvenirliğini düşürmektedir. Yöntem, aynı anda ateşlenecek olan patlayıcı miktarlarına kısıt getirmek sureti ile titreşimi düşürmeyi hedeflediği için, patlatmaların verimliliğini de düşürmektedir (daha fazla patlatma deliği, daha fazla gecikme elemanı gibi).

Bu çalışma, patlatma kaynaklı titreşimleri en aza indirebilmek için alışılagelmiş yönteme alternatif olarak geliştirilen yeni bir yöntemin (Aldaş ve Ecevitoğlu, 2008), Türkiye Kömür İşletmeleri

(TKİ) Muğla İli Yeniköy Linyit İşletmelerindeki (YLİ) bir uygulamasını içermektedir. TKİ YLİ patlatmalarından kaynaklanan titreşimleri en aza indirebilmek için, yazarlardan birinin de aralarında bulunduğu bir çalışma 1999 yılında yapılmıştır (Bilgin vd., 1999). Alışılagelmiş en yükssek parçacık hızı (PPV-peak particle velocity)- ölçekli mesafe (SD:scaled distance) grafikleri çizilerek hesaplanan ampirik formüllere göre arazi katsayıları hesaplanmış ve İkizköy Ocağı'nda bir seferde güvenle ateşlenebilecek en yüksek patlayıcı madde miktarı (ANFO:amonyum nitrat+fuel oil) $515 \mathrm{~kg}$ olarak belirlenmiştir. Bu miktarın belirlenmesinde USBM RI8507 ve OSMRE hasar ölçütleri (Siskind 1989, Dowding 1995), zeminin ve yapının etkin frekansları, büyütme faktörü ve insanların titreşimlere olan tepkileri göz önüne alınmıştır. Bu durumda, patlatmalarda aynı anda ateşlenen deliklerdeki toplam patlayıcı miktarı $515 \mathrm{~kg}$ olduğu zaman, titreşimlerin en aza indirilmesi istenen yerde ölçülecek en yüksek parçacık hızı (PPV) değerinin 3.09 mm/s olması beklenmektedir (eşitlik 1'den hesaplanmıştır).

$$
P P V=k{\frac{k}{2^{-1 / 2}}}^{-\beta}
$$

Yukarıdaki eşitlikte; PPV en yüksek parçacık hızı $(\mathrm{mm} / \mathrm{s})$, R ölçüm noktasının veya söz konusu binanın patlatma yerinden olan uzaklığı $(\mathrm{m})$, Q her gecikmede devreye giren patlayıcı madde miktarı (kg), $\mathrm{k}$ ve $\beta$ sarsıntı iletim ve sönümlenme katsayılarıdır. $\mathrm{k}$ ve $\beta$, titreşimlerin azaltılması istenen bölgede ölçülecek en az 30 patlatma kaydından elde edilmektedir.

1999 'da yapılan çalışmalara rağmen TKİ YLİ patlatmalarından kaynaklanan yer sarsıntısı şikayetlerinin devam etmesi, alışlagelmiş yöntemin soruna tam çözüm getiremediğini göstermiştir. $\mathrm{Bu}$ nedenle, yazarlar patlatmalarını minimize etmek amacıyla geliştirdikleri yeni yöntemi, bu çalışmaya konu olan YLİ (İkizköy ve Sekköy) patlatmaları için uygulamışlardır.

\section{Uygulanan Yeni Yöntemin Esasları}

$\mathrm{Bu}$ çalışmada uygulanan yöntemde, alışılagelmişin aksine, patlayıcı miktarı önemini yitirmektedir. Bu yöntem, patlatma ile ilgili parametrelere (delik sayısı, delik tasarımı, kullanılan patlayıcı miktarı, türü, deliklerin konumları, jeolojik etkiler. vs.) herhangi bir kısıt getirmemektedir. Yeni yaklaşımın esası, pilot atış kullanılarak, çoklu patlatma ile oluşan sismik dalgaların modellenmesi ve uygun gecikmeler verilerek birbirlerini söndürmelerine dayanmaktadır. Titreşim verilerinin analizinde, en büyük genlikli (Parçacık hızı, $\mathrm{mm} / \mathrm{s}$ ) sismik bileşen içindeki yine en büyük genliklerin bulunduğu zaman penceresine denk gelen dalga biçimleri üzerine yoğunlaşılır (en büyük tahribatı bu büyük genlikler vermektedir). Veri analizinden elde edilen gecikme parametreleri, gerçek grup patlatmasında uygulanır.

Yöntemin temeli pilot patlatmasına dayanmaktadır. Patlatma noktasından başlayarak hedefe ilerleyen sismik dalgalar yol boyunca çeşitli etkilerle karşılaşırlar. Patlayıcı miktarı, türü, patlayıcıkayaç etkileşimi, ayna etkisi, karmaşık jeoloji (tabakalanma, teknonik ve litolojik özellikler) bu etkilerin başlıcalarıdır. Pilot patlatma ile oluşan sismik dalgalar, tüm bu etkilerin kaydını, farklı dalga 
biçimi oluşumları ve genlik ölçeklenmeleri şeklinde üzerlerinde taşırlar. Grup patlatması içerisindeki her bir deliğin, pilot patlatmadakine eşdeğer bir dalga üreteceği varsayımından yola çıkılmıştır. Kullanılan veri işlem tekniğinin esası lineer sistemlerin önemli bir özelliği olan süperpozisyon prensibine (Oppenheim ve Schafer, 1975) dayanır.

Yeni yöntemde, patlatma kaynaklı titreşimler, alışılagelmişden farklı bir şekilde kaydedilmişlerdir (Aldaş ve Ecevitoğlu, 2008). Patlatma yapılan bölge ile titreşimlerin en aza indirilmesi hedeflenen bölge arasına yakın istasyon olarak adlandırdığımız sismograf; hedef bölgeye de uzak istasyon sismografı yerleştirilmiştir. Bu iki sismograf, kendilerine bağlı radyo alıcıları aracılığıyla, patlatma deliklerini ateşleyecek olan manyetoyu da içeren verici radyo istasyonumuzun, manyetonun ateşlenmesiyle sinyal göndermesi neticesinde tetiklenmektedir. Böylece her iki sismografın da aynı anda tetiklenmeleri sağlanmakta ve iki istasyon yöntemiyle yüzey dalgası hızı daha doğru hesaplanabilmektedir.

Pilot patlatmadan elde edilen sismik veriler, ticari bir yazılım ile sismik kayıtçılardan bilgisayara aktarıldıktan sonra, yeni geliştirdiğimiz yazılım paketi ile değerlendirilmiştir. Değerlendirme sonucu, aynı patlatmaya ait deliklerin nasıl gruplanacağı ve her gruba ne kadar gecikme verileceği belirlenmiştir. Grup patlatmaları bu parametrelere göre gerçekleştirilmiştir. Grup patlatması sonucu elde edilen ikinci veri setinden ise titreşimlerin ne kadar önlenebildiği incelenmiştir. Yazılım Paketi, verilere band geçişli süzgeç uygulayan SUZGEC, verileri incelemeye ve sismik faz hızlarını hesap etmeye yarayan HIZ, patlatma deliklerini gruplamaya ve gruplara verilecek gecikmelerin hesaplanmasına yarayan GECIKME olmak üzere üç ayrı programdan oluşmaktadır (Aldas vd. 2006; Aldas ve Ecevitoğlu, 2008).

\section{Bölgenin Jeolojik Yapısı}

Çalışma alanı ve yakın civarındaki jeolojik birimleri temsil eden genelleştirilmiş stratigrafik kesit Şekil 1'de verilmiştir.

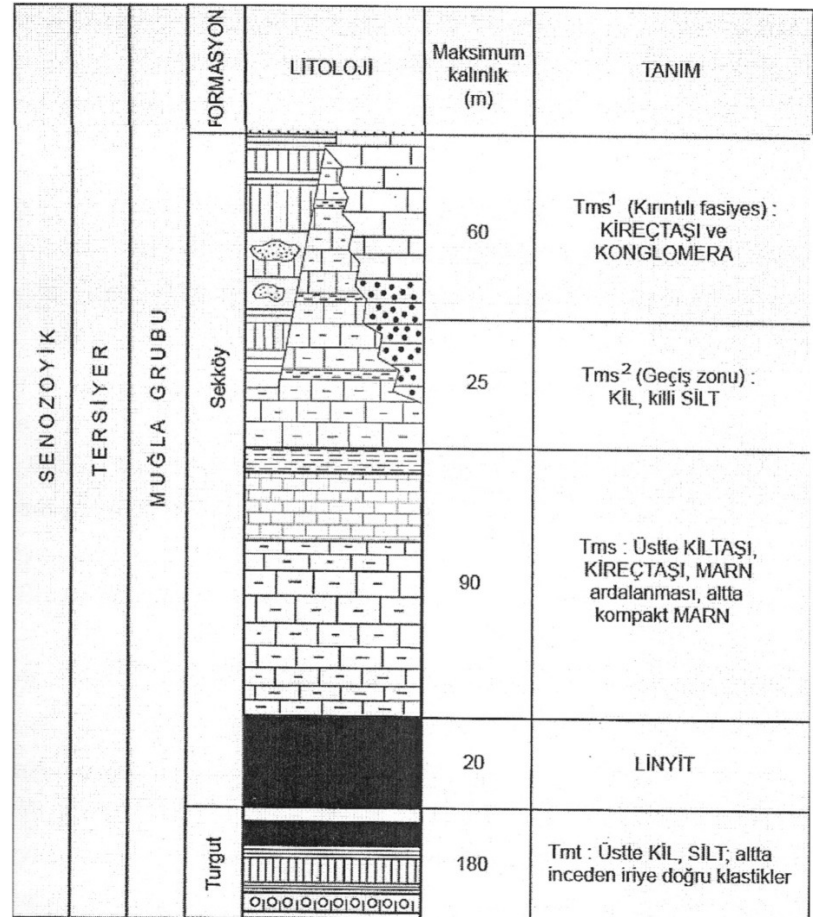

Şekil 1. Çalışma alanı stratigrafik kesiti (Ulusay,1990). 


\section{TKİ YLİ Sekköy Ocağı Patlatma Titreşimlerini En Aza İndirme Çalışmalarından Elde Edilen Bulgular}

Sekköy ocağındaki patlatmalardan termik santral binası ve lojmanlar etkilenmektedir. $\mathrm{Bu}$ nedenle, patlatma kaynaklı titreşimlerin bu bölgelerde en aza indirilebilmesi için çalışma yapılmasına karar verilmiştir. İki deneme patlatması yapılarak, santral ve lojmanlar yönlerinde titreşim kayıtları alınmış, yeni yöntem ile değerlendirilerek en uygun çözümler önerilmiştir.

\subsection{Sekköy 1. Deneme Patlatması}

Çizelge 1, birinci deneme patlatmasına ait bilgileri göstermektedir.

Çizelge 1. Sekköy'de yapılan 1.deneme patlatması parametreleri.
\begin{tabular}{|l|l|}
\hline Patlatma yeri & Sekköy \\
\hline Pilot patlatma koordinatı & $5790764111419320 \mathrm{~m}$ \\
\hline Uzak istasyon koordinatı (Termik santral) & $5775144110775320 \mathrm{~m}$ \\
\hline Yakın istasyon koordinatı & $5785934111169320 \mathrm{~m}$ \\
\hline Patlatma basamağı (Ayna) koordinatı & $5791354111513323 \mathrm{~m}$ \\
\hline Pilot-yakın istasyon mesafesi & $543 \mathrm{~m}$ \\
\hline Pilot-uzak istasyon mesafesi & $1689 \mathrm{~m}$ \\
\hline Delik sayısı & 3 pilot deliği, 27 grup deliği : 30 \\
\hline Delik boyu & $7 \mathrm{~m}$ \\
\hline Patlayıcı miktarı & $62.5 \mathrm{~kg}$ Anfo +1 kg yemleme/delik \\
\hline Ateşleme elemanı & İnfilaklı fitil gecikme rölesi \\
\hline
\end{tabular}

Patlatma bölgesinden $1689 \mathrm{~m}$ mesafedeki santral bölgesine yerleştirilen uzak istasyon sismik kayıtçısına pilot sinyali götürebilmek için, yan yana delinen 3 delik aynı anda patlatılarak pilot patlatmasını oluşturmuştur. $\mathrm{Bu}$ nedenle, "gecikme" yazılımı kullanılırken, pilot patlatmadan anlaşılması gereken, üçlü grup patlatmasıdır. Pilot 3 delik olunca, gruptaki toplam 27 delik de üçer üçer gruplanmıştır (9 adet üçlü grup). Böylece "gecikme" yazılımına 9 adet deliğin koordinatı girilmiştir.

Uzak ve yakın istasyon sismik kayıtçılardan, yeni metodolojiye uygun şekilde elde edilen pilot sinyallere, önce "süzgeç" programı ile band geçişli süzgeç uygulanmış ve veri gürültülerden arındırılmıştır. Veriler "hız" programında incelenmiş ve sismik faz hızları hesap edilmiştir. Son adımda ise, "gecikme" programı kullanılarak, önceden koordinatları alınan ve yazılıma veri olarak girilen grup patlatmasına ait delikler, gecikme gruplarına ayrılmış ve pilot sinyal ile üretilen modelgrup patlatmasına ait sismik sinyallerin birbirlerini sönümlendirmesi için en uygun gecikme aralıkları seçilmiştir.

Şekil 2'de sol üst köşede koordinatları girilen 9 adet grup patlatma deliği (her biri 3 deliği simgeliyor), aynanın konumu (düz çizgi) ve ölçüm yönü (ok işareti) görülmektedir. Pilot sinyalden modellenen grup patlatma sinyalleri yine Şekil 2'de ortada (sırasiyla yanal (Transversal), düşey (vertical), boyuna (longitudinal) ve altta her bir grup deliğine ait sinyaller (yine yanal, düşey ve boyuna bileşende) görülmektedir. Şekil 2 üst orta bölümde ise pilot sinyalin ismi gösterilmektedir (alt çizgi öncesi Yeniköy patlatma tarih ve saati, alt çizgi sonrası (u)zak (p)ilot sinyalinin süzgeç katsayılarını gösterir). $\mathrm{Bu}$ çalışmada termik santrale verilecek titreşimleri en aza indirmek hedeflendiği için, modellemede, santral yakınına konan uzak istasyon pilot sinyali kullanılmıştır. Şekil 2'nin üst sağ bölümünde ise, hangi titreşim bileşeni üzerinde modelleme yapılıyorsa ona ait gecikmesiz ((Z)ero) ve gecikmeli ((D)elay) patlatmalara ait genlikler ve bu genliklerin okunduğu zaman verilmektedir. Sekköy 1. Pilot patlatmada özellikle yanal (transversal) bileşendeki genliklerin büyük olduğu fark edildiği için, titreşimlerin azaltılması çalışmasında bu bileşene ait sinyaller kullanılmıştır. 
Sismik dalgaların yıkıcı girişime uğrayarak birbirlerini sönümlendirmelerini sağlamak amacıyla, her bir gruba uygun gecikme zamanları verilebilmesi için, model üzerinde pek çok deneme yapılmıştır. Şekil 2'de görülen gecikme aralıklarının (1 ve 2 numaralı gruplar 0 zamanında, 3 ve 4 numaralı gruplar 50ms gecikme ile, 5 ve 6 numaral gruplar 100ms gecikme ile, 7 ve 8 numaralı gruplar 150ms gecikme ile ve 9 numaralı grup 200ms gecikme ile patlatılacaktır) en iyi sonucu verdiği görülmüştür. $\mathrm{Bu}$ gecikme aralıklarının uygulanması ile yapılacak patlatmada, santrale verilecek titreşimlerde yaklaşık 8 kat azalma olacağı öngörülmüştür (Şekil 2'de sağ üst köşede önerilen gecikmesiz (TraZ: Transversal(yanal) bileşende (Z)ero (sıfır gecikme)) ve gecikmeli (TraD: Transversal(yanal) bileşende (D)elay (gecikmeli )patlatmaların yarattığı titreşim oranı, 1.11/0.14=8 dir).

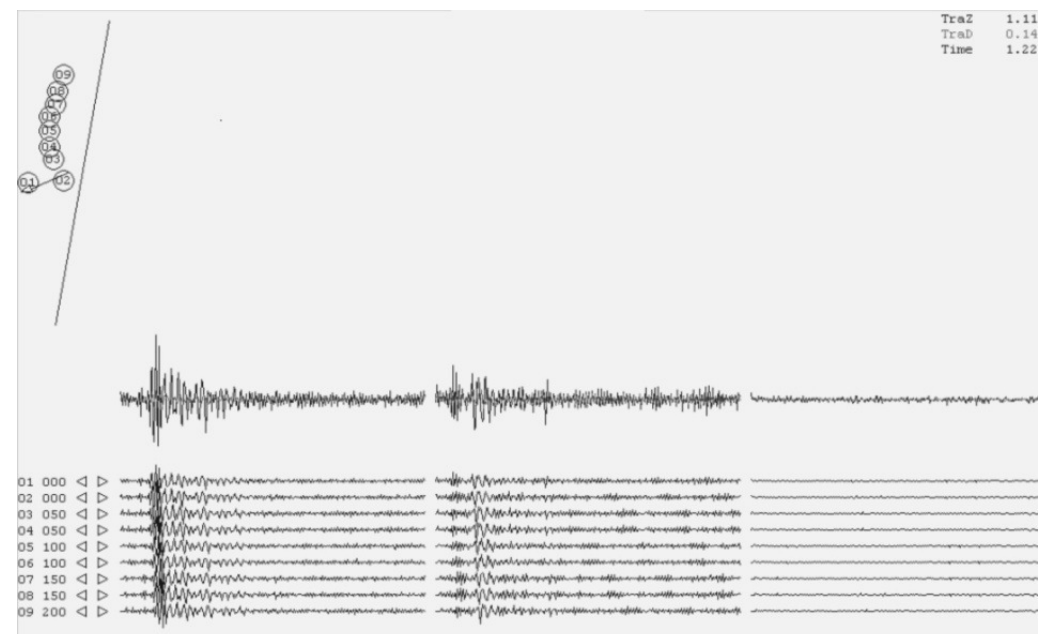

Şekil 2. Sekköy (1) deneme patlatması için, "gecikme” yazılımı ile geliştirilen modele ait ekran görüntüsü. Değerlendirmede, uzak istasyonda kaydedilen sismogram esas alınmıştır.

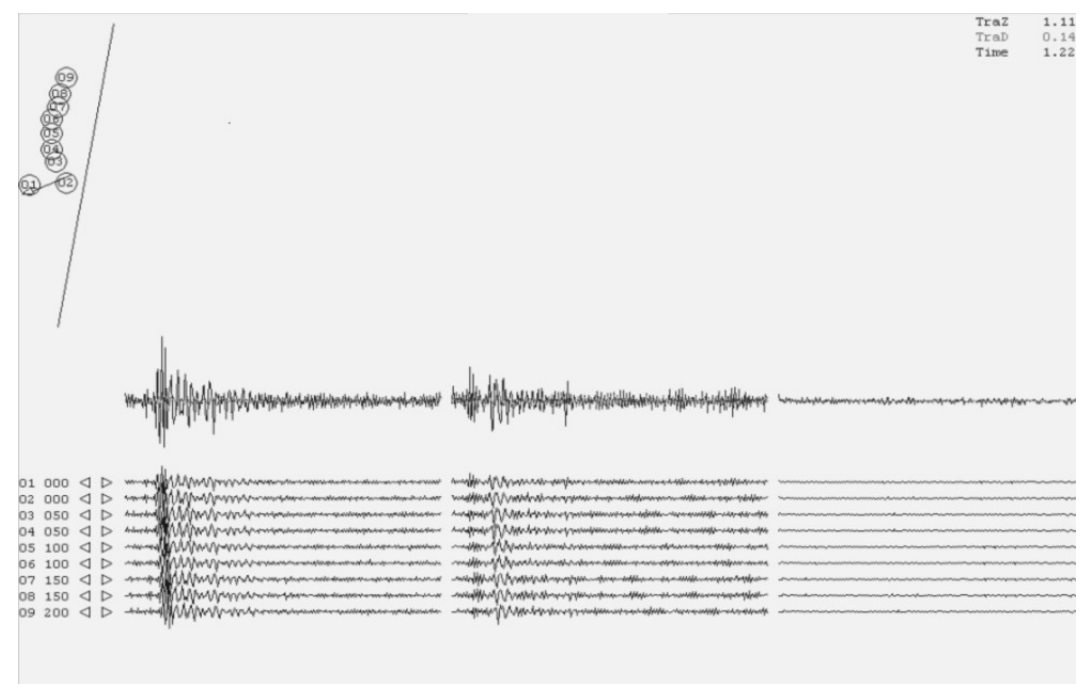

Şekil 3. Sekköy (1) deneme patlatması titreşimlerinin model verisiyle karşılaştırılması.

Modelin doğru çalışıp çalışmadığını test etmek için, model sonucu önerilen gecikme aralıkları, yine modeldeki gibi düzenlenen patlatma gruplarına uygulanmış ve alınan uzak istasyon 
titreşim verisi model sonucuyla karşılaştırılmıştır. Şekil 3'deki karşılaştırma ekranının sağ üst köşesindeki TraG, Tansverse(yanal) bileşende gerçek grup patlatmasının sismik sinyalini, TraD, Transverse(yanal) bileşende modelleme sonucu bulunan sismik sinyali göstermektedir. Zaman serisinin 1.22'.ci saniyesine bakıldığında TraD: $0.14 \mathrm{~mm} / \mathrm{s}$, TraG: $0.09 \mathrm{~mm} / \mathrm{s}$ görülmektedir. $\mathrm{Bu}$ durum, modelleme ile bulduğumuz gecikme aralıklarının uygulanması sonucu yapılan gerçek patlatmadan oluşan titreşimlerin, santral yakınında, bizim modelde öngördüğümüzden bile daha düşük olduğunu (yaklaşık 1.5 kat) göstermektedir.

\subsection{Sekköy 2. Deneme Patlatmas1}

Çizelge 2, ikinci deneme patlatmasına ait bilgileri göstermektedir.

Çizelge 2. Sekköy'de yapılan 2.deneme patlatması parametreleri.

\begin{tabular}{|l|l|}
\hline Patlatma yeri & Sekköy-kömür \\
\hline Pilot patlatma koordinatı & $5791894110206292 \mathrm{~m}$ \\
\hline Uzak istasyon koordinatı & $5784924109678303 \mathrm{~m}$ \\
\hline Yakın istasyon koordinatı & $5787804109907292 \mathrm{~m}$ \\
\hline Ayna koordinatı & $5792164110187299 \mathrm{~m}$ \\
\hline Pilot-yakın istasyon mesafesi & $506 \mathrm{~m}$ \\
\hline Pilot-uzak istasyon mesafesi & $874 \mathrm{~m}$ \\
\hline Delik sayısı & 2 pilot deliği, 20 grup deliği : toplam 22 \\
\hline Delik boyu & $14 \mathrm{~m}$ \\
\hline Patlayıcı miktarı & $150 \mathrm{~kg}$ Anfo +1kg yemleme dinamiti /delik \\
\hline Ateşleme tipi & Exel Şok tüp: 450-500ms delik içi gecikme \\
\hline
\end{tabular}

Patlatma bölgesinden 874 m mesafedeki lojmanlar bölgesine yerleştirilen uzak istasyondaki sismik kayıtçıya pilot sinyali götürebilmek için, yan yana delinen 2 delik aynı anda patlatılarak pilot patlatmasını oluşturmuştur. $\mathrm{Bu}$ nedenle, "gecikme" yazılımı kullanılırken, pilot patlatmadan anlaşılması gereken, ikili grup patlatmasıdır. Pilot 2 delik olunca, gruptaki toplam 20 delik de ikişer gruplanmıştır (10 adet ikili grup). Böylece "gecikme" yazılımına 10 adet deliğin koordinatı girilmiştir. Pilot patlatmadan elde edilen uzak ve yakın istasyon sinyalleri, yeni metodolojiye uygun biçimde veri işlemden geçirilmiştir (Süzgeç ve Hız programları ile).

Şekil 4'de sol üst köşede koordinatları girilen 10 adet grup patlatma deliği (her biri 2 deliği simgeliyor), aynanın konumu (düz çizgi) ve ölçüm yönü (ok işareti) görülmektedir. Pilot sinyalden modellenen grup patlatma sinyalleri şeklin alt bölgesinde yer almaktadır. Bu çalışmada Yeaş lojmanlarına verilecek titreşimleri en aza indirmek hedeflendiği için, modellemede, lojmanlar yakınına konan uzak istasyon pilot sinyali kullanılmıştır. Sismik dalgaların yıkıcı girişime uğrayarak birbirlerini sönümlendirmeleri için gruplara verilmesi gereken en uygun gecikmeler (1. ve 2. grup sıfır zamanında, 3. ve 4. grup 50ms, 5. ve 6. grup $100 \mathrm{~ms}$, 8.grup 150ms, 7.ve 9.grup 200ms, 10.grup 250ms) uygulanmıştır. Şekil 4'de görüldüğü üzere, böyle bir gecikme düzeninin kullanılması ile özellikle düşey titreşim bileşeninde çok büyük bir sönümlenme olacağı (yaklaşık 15 kat), model tarafından öngörülmektedir. (Şekil 4'de sağ üst köşede boyuna bileşen için gecikmeli ve gecikmesiz patlatmaların yarattı̆̆ titreşim oranı, 12.96/0.88=14.7 dir).

Modeli test etmek için, modelin öngördüğü gecikme aralıkları, yine modeldeki gibi düzenlenen patlatma gruplarına uygulanmış ve alınan uzak istasyon titreşim verisi model sonucuyla karşılaştırılmıştır. Şekil 5 bu karşılaştırmayı göstermektedir. Modelleme boyuna bileşendeki genlikler daha yüksek olduğu için bu bileşene göre yapılmıştır. Bu yüzden karşılaştırma ekranında boyuna bileşende gerçek patlatma sinyalinin genliği (siyah) ile modelin öngördüğü genlikler (gri) arasında bir uyum gözlenmektedir. Sağ üst köşede $2.15^{\prime}$.ci saniyedeki boyuna bileşene ait gerçek ve model sinyal genlikleri de bunu göstermektedir. Modelleme yanal ve düşey bileşen göre değil, de genliklerin büyük olduğu boyuna bileşene göre yapıldığı için yanal ve düşey bileşenlerde gerçek ve sentetik sinyal 
uyumunun bozulduğu görülmektedir. Bunun bir sebebi de, modelde sadece işletmenin elinde olan gecikme aralıklarının uygulanmak zorunda kalınmasıdır. İşletmede mevcut olan $50 \mathrm{~ms}$ ve $100 \mathrm{~ms}$ gecikme elemanları kullanılarak modelleme yapılmış, gruplar arasına $50 \mathrm{~ms}$ ve $100 \mathrm{~ms}$ 'nin katlarından başka gecikmeler (örneğin $90 \mathrm{~ms}, 110 \mathrm{~ms}, 230 \mathrm{~ms}, 320 \mathrm{~ms}$ ) verilemediği için, dalgaların yıkıcı girişimlerini sağlamada ancak belli ölçüde başarılı olunabilmiştir. Buna rağmen, zaman serisinin 2.15. saniyesinde boyuna bileşen sinyaline bakıldığında (Şekil 5 săg üst köşe, LonG: Longitudinal (boyuna) bileşen gerçek grup patlatması titreşim genliğini (siyah), LonD: Longitudinal (boyuna) bileşen model sinyalin genliğini (gri) göstermektedir), model, Yeaş Lojmanlarında $2.47 \mathrm{~mm} / \mathrm{s}$ titreşim genliği ölçüleceğini öngörürken, modelleme ile bulunan gecikme tasarımı uygulandığında, gerçek patlatmadan aynı saniyede $2 \mathrm{~mm} / \mathrm{s}$ titreşim genliği ölçülmüştür. Zaman serisinin geneline bakıldığında ise, model, titreşim genliklerinde biraz daha fazla düşüş olacağını söylese de, önerilen gecikme tasarımı uygulanarak yapılan ve toplamda 3 ton patlayıcının patlatıldığı bu deneme patlatmasında Yeaş Lojmanlarında (874 m uzakta) ölçülen gerçek değerler de oldukça düşüktür.

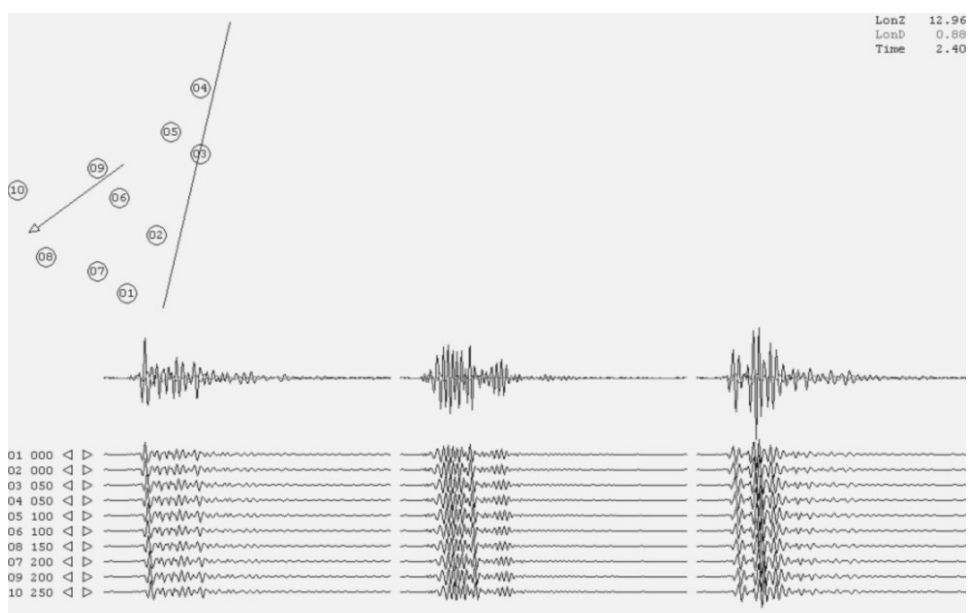

Şekil 4. Sekköy (2) deneme patlatması için, "gecikme" yazılımı ile geliştirilen modele ait ekran görüntüsü. Değerlendirmede, uzak istasyonda kaydedilen sismogram esas alınmıştır.

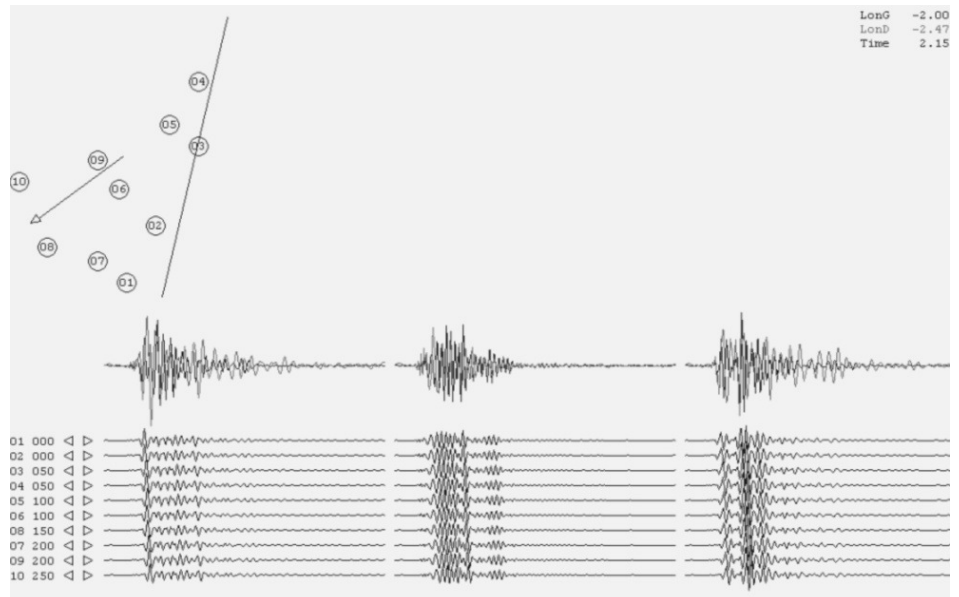

Şekil 5. Sekköy 2.deneme patlatması titreşimlerinin model verisiyle karşılaştırılması. 


\section{TKİ YLİ İkizköy Ocağı Patlatma Titreşimlerini En Aza İndirme Çalışmaları}

Çizelge 3, İkizköy ocağında yapılan deneme patlatmasına ait bilgileri göstermektedir.

Çizelge 3. İkizköy ocağı deneme patlatması parametreleri.

\begin{tabular}{|l|l|}
\hline Patlatma yeri & İkizköy \\
\hline Pilot patlatma koordinatı & $5784774113341232 \mathrm{~m}$ \\
\hline Uzak istasyon koordinatı (Yeniköy) & $5777454111875324 \mathrm{~m}$ \\
\hline Yakın istasyon koordinatı & $5780304112436384 \mathrm{~m}$ \\
\hline Patlatma Basamağı (Ayna) koordinatı & $5784274113395232 \mathrm{~m}$ \\
& $785104113360233 \mathrm{~m}$ \\
\hline Pilot-yakın istasyon mesafesi & $1009 \mathrm{~m}$ \\
\hline Pilot-uzak istasyon mesafesi & $1638 \mathrm{~m}$ \\
\hline Delik sayısı & 5 pilot deliği, 20 grup deliği : toplam25 \\
\hline Delik boyu & $7 \mathrm{~m}$ \\
\hline Patlayıcı miktarı & $40 \mathrm{~kg}$ Anfo +0.5kg yemleme dinamiti /delik \\
\hline Ateşleme tipi & Elektrikli kapsül (30ms...120ms) \\
\hline
\end{tabular}

İkizköy'de yapılan patlatmalardan kaynaklı titreşimlerden Yeniköy isimli köyün sakinleri şikayetçi olduğu için, hedef Yeniköy seçilmiş ve uzak istasyon buraya kurulmuştur. Patlatma bölgesinden 1638 m mesafedeki uzak istasyondaki sismik kayıtçıya pilot sinyali götürebilmek için, yan yana delinen 5 delik aynı anda patlatılarak pilot patlatmasını oluşturmuştur. Bu nedenle, "gecikme" yazılımı kullanılırken, pilot patlatmadan anlaşılması gereken, beşli grup patlatmasıdır. Pilot 5 delik olunca, gruptaki toplam 20 delik de beşer gruplanmıştır. ( 4 adet beşli grup). Böylece "gecikme" yazılımına 20 adet delik koordinatı değil, 4 adet deliğin koordinatı girilmiştir. Pilot patlatmadan elde edilen uzak ve yakın istasyon sinyalleri, yeni metodolojiye uygun biçimde veri işlemden geçirilmiştir (Süzgeç ve Hız programları ile).

Şekil 6'da sol üst köşede, koordinatları girilen 4 adet grup patlatma deliği (her biri 5 deliği simgeliyor), aynanın konumu (düz çizgi) ve ölçüm yönü (ok işareti) görülmektedir. Pilot sinyalden modellenen grup patlatma sinyalleri şeklin alt bölgesinde yer almaktadır. Bu çalışmada Yeniköy’e verilecek titreşimlerin en aza indirilmesi hedeflendiği için, modellemede, Yeniköy'deki uzak istasyon pilot sinyali kullanılmıştır. Sismik dalgaların yıkıcı girişime uğrayarak birbirlerini sönümlendirmeleri için gruplara verilmesi gereken en uygun gecikmelerin seçiminde zorlanılmıştır. Bunun sebebi, İkizköy ocağının patlatmalarını yapan müteahhit firmanın çok sınırlı bir aralıkta gecikme elemanları kullanmasıdır (30, 60, 90 ve $120 \mathrm{~ms})$. Böyle dar bir gecikme aralığı seçenekleri ile modelleme yaparak, titreşimleri olabildiğince aza indirmeye çalışılmıştır. Şekil 6'da da görüldügüu üzere, birinci grup $30 \mathrm{~ms}$ gecikme ile ikinci grup $60 \mathrm{~ms}$, üçüncü grup $90 \mathrm{~ms}$ ve son grup $120 \mathrm{~ms}$ gecikme ile patlatılacak şekilde bir modelleme yapılmıştır. Böyle bir gecikme düzeninin kullanılması ile özellikle yanal titreşim bileşeninde tatminkar bir sönümlenme olacağı, model tarafından öngörülmektedir. (Şekil 6' da sağ üst köşede yanal bileşen için 1.26.saniyede, gecikmesiz patlatmanın titreşim genliği (TraZ $0.14 \mathrm{~mm} / \mathrm{s}$ ilen, gecikmelinin (TraD) $0.02 \mathrm{~mm} / \mathrm{s}$ 'dir). Modeli test etmek için, modelin öngördüğü gecikme aralıkları, yine modeldeki gibi düzenlenen patlatma gruplarına uygulanmış ve alınan uzak istasyon titreşim verisi model sonucuyla karşılaştırılmıştır. Şekil 7 bu karşılaştırmayı göstermektedir. Karşılaştırmak için, zaman serisinin 1.51. saniyesinde yanal bileşen sinyali esas alınmıştır (Şekil 7 sağ üst köşe). Gerçek patlatma sinyalinin genliği $0.05 \mathrm{~mm} / \mathrm{s}$, modelin öngördüğü genlik $0.03 \mathrm{~mm} / \mathrm{s}$ 'dir. Ocaktaki patlatma işlerini yürüten müteahhitin daha geniş aralıklarda gecikme elemanları temin etmesi durumunda, modelin öngörüsünde iyileştirmeler yapmak mümkündür. 


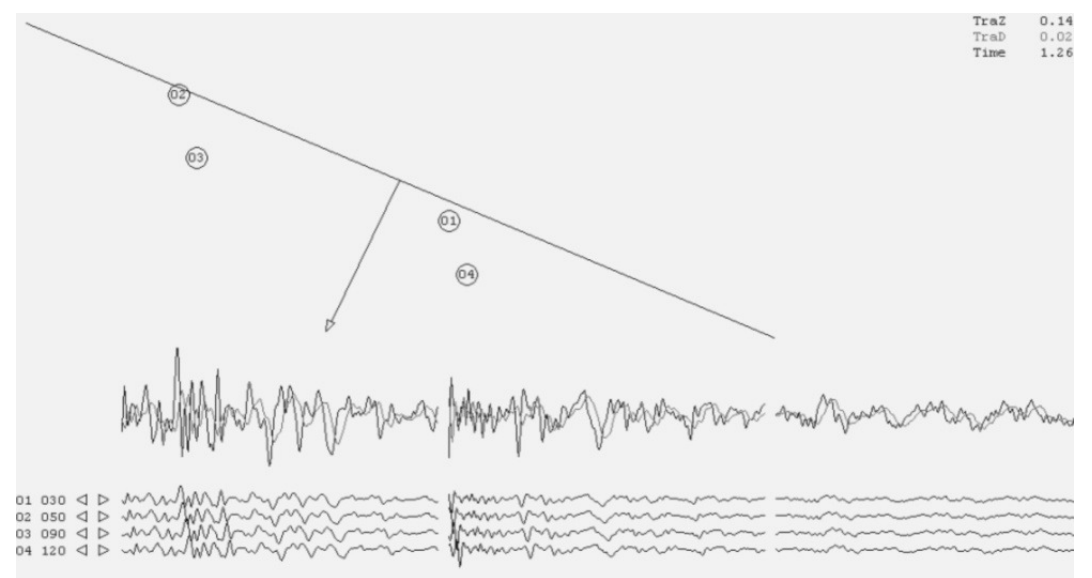

Şekil 6. İkizköy deneme patlatması için, "gecikme” yazılımı ile geliştirilen modele ait ekran görüntüsü. Değerlendirmede, uzak istasyonda kaydedilen sismogram esas alınmıştır.

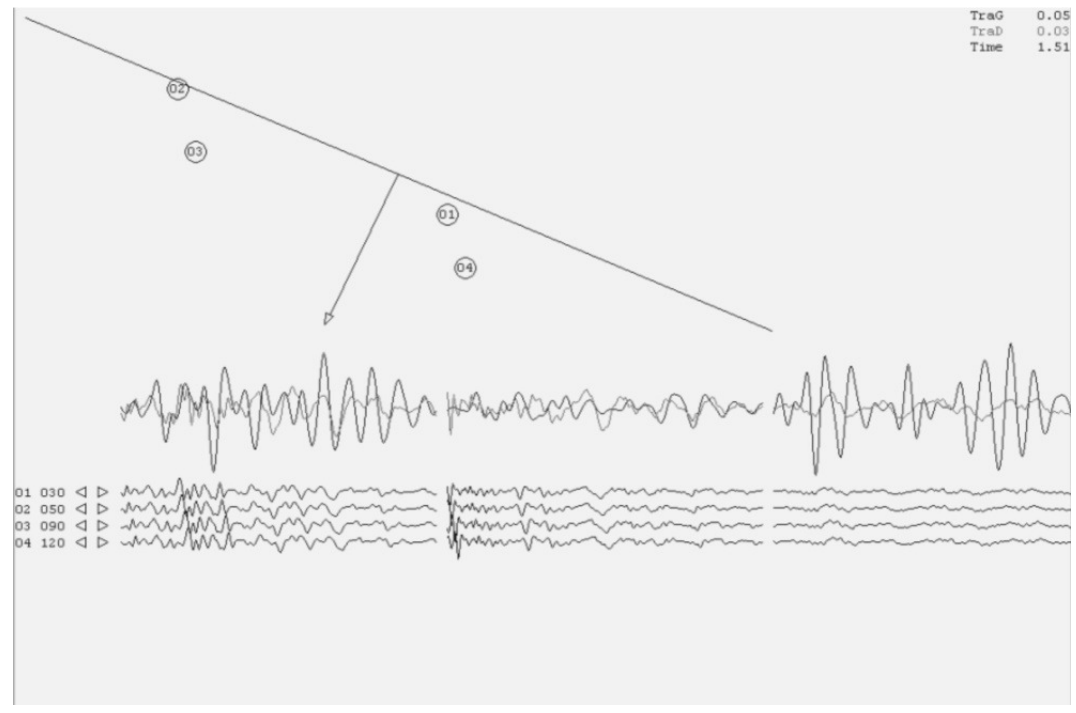

Şekil 7. İkizköy deneme patlatması titreşimlerinin model verisiyle karşılaştırılması

\section{Tartışma}

TKİ YLİ işletmesinde daha önce yapılan (Bilgin vd., 1999) titreşimleri en aza indirme çalışmasında, hedef bölgedeki arazi katsayılarını bulabilmek için 10 patlatma yapılmış ve iki istasyonla toplam 20 kayıt elde edilmiştir. Yeni yöntemde ise sadece 1 pilot patlatma sinyalinin hedeflenen güzergahta ölçülmesi ile modelleme yapılabilmiştir (Pilot sinyal, seyahat ettiği bölgenin tüm karmaşık jeolojisini üstünde bilgi olarak getirir). Ayrıca, patlayıcı miktarına ve patlatma düzenine karışılmamış, işletmenin her zaman yaptığı patlatma düzenini uygulamaları istenmiş̧ir. Müdahele edilen tek nokta, patlatma gruplarına verilen gecikme süreleri olmuştur. İşletmecilerin, genel tavrının grup aralarına $25 \mathrm{~ms}-50 \mathrm{~ms}$ gibi küçük gecikmeler vermek olduğu anlaşılmış ve bu küçük gecikme 
elemanlarının titreşimleri söndürmek yerine çoğu kez yapıcı girişime neden olup arttırdığı uyarısı yapılmıştır.

Patlatmalarda, 25-50 ms gibi küçük gecikme elemanlarının kullanılması, sismik dalgaların yıkıcı girişimlerini (destructive-interference) sağlayamadığı gibi, sismik sinyal üzerinde tümleme (integral) etkisi yaratılmasına neden olur. Bu durum büyük genlikli, uzun dalga boylu yüzey dalgalarının güçlenmesi anlamına gelir. Uzak mesafelere ulaşabilen bu tür dalgalar, gerek zemini, gerekse yapıları kolayca rezonansa getirerek hasar miktarını arttırırlar. 25-50 ms gibi küçük gecikme elemanları kullanmanın tek faydası, ortamın sismik dalga üreten ve ileten sağlam yapısını bozarak ortamı plastik hale getirmek, böylece takip eden patlatmaların titreşim etkilerini azaltmaktır. Öte yandan, açılmaya başlayan yarık, çatlak ve göçüklerden kaçan patlama kökenli gazlar da, patlama gücünü azaltırlar (Aldaş vd. 2006).

Yeni yöntem, patlatmaların yarattığı yüzey dalgalarının bastırılabilmesi için, $100 \mathrm{~ms}$ ve daha büyük gecikmelere ihtiyaç olduğunu göstermiştir. Bunun nedeni, patlatma kaynaklı yüzey dalgalarının düşük frekanslara (1-5 Hz gibi) sahip olmasıdır. Metodoloji kapsamında belirlenen gecikme zamanlarının patlatma grubuna uygulanması aşamasında, $9 \mathrm{~ms}, 17 \mathrm{~ms}$ veya en çok $25 \mathrm{~ms}$ gibi küçük gecikme elemanlarına gereksinim vardır. Örneğin $130 \mathrm{~ms}$ lik bir gecikme vermek için, 5 ms'lik bir hata göz önüne alındığında, $100 \mathrm{~ms}+25 \mathrm{~ms}$ gecikmeli iki eleman yeterli olacaktır. Bu bilgilerin 1 şığı altında, istenilen gecikme zamanına en az sayıda gecikme elemanı kullanılarak ulaşabilecek şekilde, gecikme elemanı stoğunun yapılması gerekir.

Metodoloji kapsamında kullanılan cihazlar, tek patlatma için yalnızca bir doğrultuda titreşim analizi yapılmasına izin vermektedir. Patlatmalardan etkilenecek yerleşim birimlerinin birden fazla olduğu, veya yerleşim biriminin geniş alana yayıldığı sahalarda, aynı patlatma için birden fazla doğrultuda ve noktada titreşim analizi yapılması gerekebilir. Bu durumda kullanılacak titreşim ölçer sayısının arttırılmasında fayda vardır.

\section{Sonuç}

Bu çalışma, patlatma kaynaklı titreşimlerin en aza indirilmesinde, alışılagelmiş yöntemden farklı olarak geliştirilen ve yüzey dalgalarının birbirleriyle sönümlendirilmelerine dayanan yöntemin TKİ YLİ Sekköy ve İkizköy ocaklarındaki uygulamasını anlatmaktadır. Yapılan uygulamalarda gerçek grup patlatması sinyalleri ile modellenen grup patlatması sinyallerinin örtüşmesi, yöntemin iyi çalıştı̆̆ını göstermektedir. Başka bir deyişle, yüzey dalgalarının uygun gecikmeler verilerek birbirlerine söndürülmesi prensibi ile YLİ Sekköy ve İkizköy'deki patlatma titreşimleri önemli ölçüde azaltılmıştır. Alışılagelmiş yöntemde olduğu gibi patlayıcı miktarına ve işletmenin uyguladığı patlatma düzenine kısıt getirilmediği için, YLİ patlatmaları, işletmenin istediği şekilde uygun parçalanma sağlanarak ve titreşimler en aza indirilerek yapılabilmiştir.

Yöntemin alışllagelmiş yöntemlere göre üstünlügüü, (i) değerlendirmelerin, yalnızca en büyük parçacık hızına (PPV) dayandırılmaması; dalga biçimi, frekans içeriği ve titreşim sürecinin de dikkate alınması, (ii) patlayıcı miktarına bir kısıt getirilmemesi ve işletmenin uyguladığı patlatma düzenine karışılmaması, (iii) tek bir kayıt istasyonundan elde edilen titreşim kaydı ile dahi (sismik faz hızı hesaplanmayacaksa) analiz yapilabilmesidir.

\section{Teşekkür}

Yazarlar, arazi uygulamalarında her türlü desteği veren TKİ YLİ yetkililerine, veri toplama aşamasındaki yardımlarından dolayı Jeofizik Yük. Mühendisi Betül Ünüçok'a ve Jeofizik Mühendisi Özgür Sağol'a teşekkür ederler.

\section{Kaynaklar}

Adhikari, G.R., Theresraj, A.I., Venkatesh, S., Balachander, R., Gupta, R.N. 2004. Ground vibration due to blasting in limestone quarries. Fragblast - International Journal of Blasting and Fragmentation 8 (2): 85-94. 
Aldas, G.G.U, Ecevitoğlu, B. 2008. Waveform analysis in mitigation of blast-vibration. Journal of Applied Geophysics 66: 25-30.

Aldas, G.G.U., Ecevitoglu, B., Can, A., Unucok, B., Sagol, O. 2006. TKİ YLİ Sekköy ocağında patlatma kaynaklı titreşimlerin en aza indirilmesi çalışma raporu.

Anderson, D.A., Winzer, S.R., Ritter, A.P. 1982. Blast design for optimizing fragmentation while controlling frequency of ground vibration. Proceedings of the 8th Conference on Explosives and Blasting Technique. Proceeding Book: 69-89 1982, New Orleans.

Bilgin, H.A., Esen, S., Kılıç, M., Aldas, G.G.U. 2000. Yeniköy Linyit İşletmesinde Patlatma Kaynaklı Yer Sarsıntılarının İncelenmesi. 4. Delme ve Patlatma Sempozyumu. Bildiriler Kitabı:147158. 18-19 Nisan 2000, Ankara.

Bollinger, G.A. 1971. Blast Vibration Analysis. Southern Illinois University Press: 132, Carbondale and Edwardsville.

Chen, G., Huang, S. 2001. Analysis of ground vibrations caused by open pit production blasts: a case study. Fragblast - International Journal of Blasting and Fragmentation 5 (1), 91-107.

Dowding, C.H. 1985. Blast Vibration Monitoring and Control. Prentice-Hall, Inc.: 297, Englewood Cliffs, NJ.

Hoshino, T., Mogi, G., Shaoquan, K. 2000. Optimum delay interval design in delay blasting. Fragblast - International Journal of Blasting and Fragmentation 4:139-148.

Oppenheim, A.V. and Schafer, R.W. 1975. Digital Signal Processing. Prentice Hall: 585 pages, London.

Persson, P.A., Holmberg, R., Lee, J. 1994. Rock Blasting and Explosives Engineering. CRC Press, Inc.:367, New York.

Siskind, D.E. 2000. Vibrations from Blasting. International Society of Explosives Engineers: 120 pages, New York.

Siskind, D.E., Stagg, M.S., Kopp, J.W., Dowding, C.H. 1980. Structure response and damage produced by ground vibrations from surface mine blasting. USBM RI 8507: 77, Boston.

Siskind, D.E., Crum, S.V., Otterness, R.E., Kopp, J.W. 1989. Comparative study of blasting vibrations from Indiana surface coal mine. USBM RI 9226: 41, Boston.

Tripathy, G. and Gupta, I.D. 2002. Prediction of ground vibrations due to construction blasts in different types of rock. Rock Mechanics and Rock Engineering 35 (3): 195-204.

Muller, B. 1997. Adapting blasting technologies to the characteristics of rock masses in order to improve blasting results and reduce blasting vibrations. Fragblast 1: 361-378.

Muller, B., Hohlfeld, T.h. 1997. New possibility of reducing blasting vibrations with an improved prognosis. Fragblast 1: 379-392.

Ulusay, R. ve Yoleri, M.F., 1990. T.K.İ. G.E.L.İ Yatağan (Muğla) Eskihisar açık işletmesi şev stabilitesi etüdü raporu. MTA rapor no: 9089, Ankara (Türkçe). 